\title{
Investigation of the Valuation Model and Asset Allocation Based on Duration
}

\author{
Yuchen Liu, \\ ${ }^{1}$ School of Economics, Ocean University of China, Qingdao, Shandong 266000, China \\ *Corresponding author. Email: liuyuchen@stu.ouc.edu.cn
}

\begin{abstract}
Valuation is an important part of asset estimation and allocation, which are utilized in previous studies to evaluate the value of investment based on different models. In this paper, the duration is investigated as a valuation model in order to access the efficiency in asset allocation and is compared with the normal way which uses the discount rate. The way to calculate the duration and the mean to obtain the amounts of asset in portfolio by using duration are demonstrated. Besides, the empirical study and the sensitive analysis are carried out to find the elements that affects the present value and the amount of asset in portfolio. These results pave a new path to calculate present value by using duration, which will be efficient in valuation during investment.
\end{abstract}

Keywords: duration, valuation model, asset allocation.

\section{INTRODUCTION}

Valuation plays an important role in asset estimation, which shows the performance of asset and gives investor advice for investment. Besides, it can be a way to show the ability of price finding in financial market, which will be useful for evaluating the asset value and allocating their capital. As for duration, it is a definition of weighted present value and can be seen as a definition of time. Duration can be a good index to estimate asset in financial market.

In the study of pricing model, Le. et al. [1] developed pricing \& compensation schemes under different demand \& supply. A, M. R. et al. [2] generalized the Constant Elasticity of Variance (CEV) model to a fractional-CEV model in order to capture the long memory effect and show the negative relationship between price and return volatility. Siu, T. K. , Elliott. [3] used a nonlinear time series model to combine both the self-exciting threshold autoregressive (SETAR) model and the generalized autoregressive conditional heteroscedastic (GARCH) model. Baamonde-Seoane. et al. [4] presented a valuation method for Renewable Energy Certificates (RECs) or green certificates. Thorsten and Fatemeh [5] extended the capital asset pricing model (CAPM) to situations where a subset of investors is not the mean-variance optimizers.
For asset allocation, Ge et al. [6] investigated the effects of political background on China's household asset allocation behavior by using 2014-2018 households panel data from the China Family Panel Studies (CFPS). Based on their results, it is found that political background has a significant positive impact on the financial market participation. Shen et al. [7] studied the role of white precious metals in the allocation of general asset. Specifically, silver, platinum and palladium were selected to test whether these three kinds of white precious metals affect hedging risk in general asset (stocks, bonds and foreign exchange). Du et al. [8] studied the connection of backward linear quadratic mean-field-game (LQ MFG) and forward LQ MFG with terminal constraint. Furthermore, the decoupled optimal strategies of this MFG are solved explicitly by introducing some Riccati equations. As an illustration, some simulations of the optimal asset allocation for the firm and pension funds are further studied. Huang, Z. [9] analyzed risk assets and family financial asset allocation structure of mutual influence and role. In detail, an empirical analysis of the influencing factors for financial asset allocation structure of Chinese residents is carried out by using Probit model and Tobit model. Pay attention to risk assets, family income and other factors, a deeper understanding of family financial asset investment circumstances is presented based on CHFS data and the theory of asset investment behavior. H Kato. [10] 
proposed the usage of "risk factors" instead of asset classes, which achieves the portfolio diversification based on the decomposition of portfolio risk into risk factor contribution.

Duration is came up by F.R.Macaulay in 1938 [11]. It is based on discounted cash flow (DCF), which is the value of expected cash receipts and expenditures at a common date calculated using net present value. In this case, duration model can be used as a valuation or pricing model.

In this paper, the efficiency of duration will be investigated in valuation and asset allocation. Specifically, the Macaulay Duration and Modified Duration are utilized to calculate the price and estimate the bond. Besides, the error is checked with present value when the yield to maturity changes from smallscale to large-scale. According to the results, it is efficient to evaluate the price of bond using duration when the yield to maturity is change from small-scale while has huge error when yield to maturity change a lot. Moreover, the weight of in portfolio is calculated when allocate the asset. The sensitive analysis also exhibits the impact on present value and amounts of units when different elements change.

The rest of the paper is organized as follow. Section 2 will introduce the method to calculate the Macaulay Duration, Modified Duration, the present value with the zero-coupon, and bond with fixed coupon, grow coupon as well as normal coupon bond. Besides, the weight of each bond in portfolio is investigated. Section 3 presents the empirical study based on the duration model. In detail, several examples are utilized to test the present value of bond and study the effect on the present with change of yield to maturity, grow rate and the effect on amount of bond on portfolio when yield to maturity change. Section 4 will discuss the assumption and the drawbacks of this model of this model. Eventually, a brief summary is given in Section 5 .

\section{METHOD}

Generally, there are two ways to estimate the bond valuation. Yield to maturity is one path to evaluate the bond, which is seen as the discount rate while duration is another one. In this part, the definition of duration, the way to calculate the Macaulay Duration and the Modified Duration and the price of bond will be introduced. Besides, the means are investigated to make the derivations of valuing the assessment of different kinds of bond with zero-coupon bond, bond with fixed coupon, coupon bond with a grow rate and the normal coupon bond. Furthermore, the way to calculate the weight of each bond in portfolio is also presented.

\subsection{Duration Calculation}

\subsubsection{Macaulay Duration (Duration)}

According to F. R. Macaulay, duration means the weighted average of the time required for cash flow payment of bonds in each period. Therefore, the present value of each year and the holding time will influence the duration. The following equation will show the way to calculate the Macaulay Duration.

$$
\mathrm{D}=\sum_{\mathrm{t}=1}^{\mathrm{n}} \frac{\mathrm{t} \times \mathrm{PV}_{\mathrm{t}}}{\mathrm{PV}_{\mathrm{t}}}
$$

(1)

where PV means present value and $\mathrm{t}$ means time, $\mathrm{n}$ means the maturity.

\subsubsection{Modified Duration}

Modified Duration is applied to calculate the percent change in yield to maturity and the change in price of bond directly. It is a correction of Macaulay duration in considering of the yield to maturity. The yield to maturity and the Macaulay Duration will influence the Modified Duration. Typically, it can be obtained as:

$\mathrm{MD}=-\frac{1}{\mathrm{P}} \times \frac{\partial P}{\partial y}=\frac{1}{1+\mathrm{y}} \sum_{\mathrm{t}=1}^{\mathrm{n}} \frac{\mathrm{t} \times \mathrm{PV}_{\mathrm{t}}}{\mathrm{PV}_{\mathrm{t}}}=\frac{1}{1+\mathrm{y}} \times \mathrm{D}$

where MD means Modified Duration, $\mathrm{P}$ means price, y means yield to maturity, D means Macaulay Duration.

\subsection{Calculate bond's present value}

This part includes bond like the zero-coupon bond, bond with foxed coupon, bond with growing coupon and normal bond with different coupon. In this part, it is assumed that the coupon will be paid at the end of each year.

\subsubsection{Zero-coupon bond}

Zero-coupon means there is no cash flow happened during the maturity and pay the whole face value at the end of the maturity. The present value equals to the discount of the final face value.

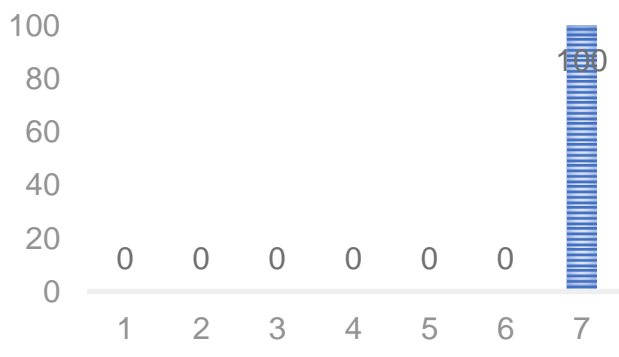

Figure 1 Cash flow of zero-coupon bond 
For convenience of display, a zero-coupon with the maturity of 7 with 100 face value is chosen for illustration. Figure 1 shows the cash flow of zerocoupon bond. The present value can be calculated by the following:

$$
\mathrm{PV}=\frac{\mathrm{FV}}{(1+\mathrm{y})^{\mathrm{t}}}
$$

where FV means face value.

\subsubsection{Bond with fixed coupon}

Coupon bond with fixed bond means a fixed cash flow will happen on special days during the maturity and the face value will be paid at the end of maturity. The present value of the bond with fixed coupon equals to the sum of the discounted cash flow of each year.

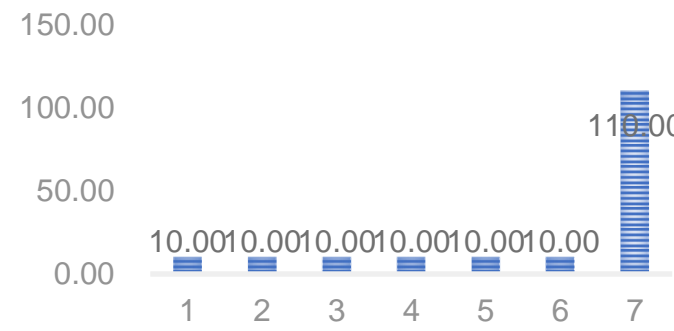

Figure 2 Cash flow of bond with fixed coupon

For convenience of display, a same bond as Sec. 2.2.1 is assumed (maturity of 7 with 100 face value). The fixed coupon bond rate is $10 \%$. Figure 2 gives the cash flow of the fixed coupon bond. The cash flow of this bond will be 10 each year and 110 at the end of maturity.

The present value can be calculated:

(4)

$$
\mathrm{PV}=\sum_{\mathrm{t}=1}^{\mathrm{n}-1} \frac{\mathrm{CF}}{(1+\mathrm{y})^{\mathrm{t}}}+\frac{\mathrm{FV}+\mathrm{CF}}{(1+\mathrm{y})^{\mathrm{n}}}
$$

where CF means cash flow.

\subsubsection{Bond with coupon growing}

The bond with coupon growing means the coupon will grow at a growth rate $(\mathrm{g})$. The present value equals to the sum of the discounted value of each year.

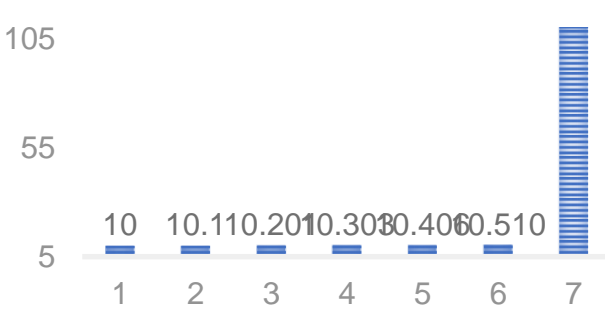

Figure 3 Cash flow of bond with growing coupon
Figure 3 illustrates the cash flow of growing coupon bond, where the cash flow at the first year will be 10 and grow at the rate of $1 \%$ each year, the payment will be 110.615 at the last year. There is an assumption that the coupon rate is $10 \%$, the growth rate $(\mathrm{g})$ is $1 \%$ and the face value is still 100 with the maturity is 7 . The present value follows:

$\mathrm{PV}=\sum_{\mathrm{t}=1}^{\mathrm{n}-1} \frac{\mathrm{FV} \times \mathrm{r} \times(1+\mathrm{g})^{\mathrm{t}-1}}{(1+\mathrm{y})^{\mathrm{t}}}+\frac{\mathrm{FV}\left(1+\mathrm{r} \times(1+\mathrm{g})^{\mathrm{n}-1}\right)}{(1+\mathrm{y})^{\mathrm{n}}}$

where g means growth rate.

\subsubsection{Normal coupon bond}

The normal coupon bond will have different cash flow each year and the yield to maturity is different as well. As a consequence, the present value is the sum of the discounted value of each year. Figure 4 presents the cash flow of this type of bond, where the cash flow is general in each year.

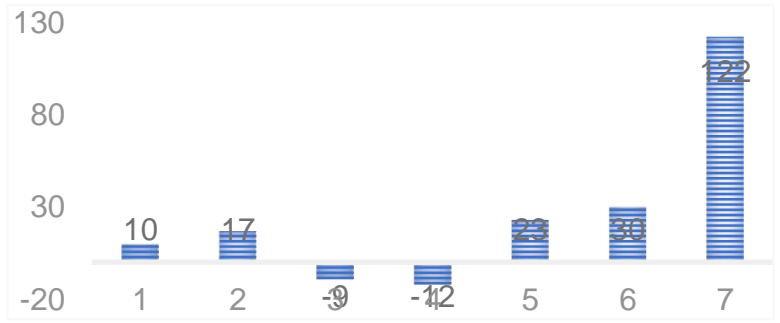

Figure 4 Cash flow of normal coupon

The present value is:

$\mathrm{PV}=\frac{\mathrm{CF}_{1}}{\left(1+\mathrm{y}_{1}\right)}+\frac{\mathrm{CF}_{2}}{\left(1+\mathrm{y}_{2}\right)^{2}}+\frac{\mathrm{CF}_{3}}{\left(1+\mathrm{y}_{3}\right)^{3}}+\ldots+\frac{\mathrm{CF}_{\mathrm{n}}}{\left(1+\mathrm{y}_{\mathrm{n}}\right)^{\mathrm{n}}}$

\subsection{Calculate the price of bond using Modified Duration}

In this part, the way to calculate the price of bond by using duration as a valuation model is investigated, i.e., one can use the duration of bonds to estimate the value of bond.

$$
\begin{aligned}
& \mathrm{MD}=-\frac{1}{\mathrm{P}} \times \frac{\partial P}{\partial y}=\frac{1}{1+\mathrm{y}} \sum_{\mathrm{t}=1}^{\mathrm{n}} \frac{\mathrm{t} \times \mathrm{PV}_{\mathrm{t}}}{\mathrm{PV}_{\mathrm{t}}}=\frac{1}{1+\mathrm{y}} \times \mathrm{D} \\
& (7) \\
& \frac{\Delta P}{\mathrm{P}}=-\mathrm{MD} * \Delta \mathrm{y}
\end{aligned}
$$

As the Modified Duration (MD) can represent the effect on the percent change in price with the percent change of yield straight. When yield to maturity rises, the new price of the bond equal to:

$$
P^{*}=P(1-M D \times \Delta y)
$$

As for yield to maturity falls, the new price of the bond equal to: 


$$
P^{*}=P(1+M D \times \Delta y)
$$

In equation (8) and (9), $\mathrm{P}^{*}$ means price after yield to maturity changing.

\subsection{Calculate the weight of each bond in a portfolio}

In order to calculate the weight of each bond, it is necessary to consider the portfolio is made by several bond. Thus, the weight of each bond can be decided by the duration of the bond and the duration of the portfolio. The duration of portfolio equals to the sum of the duration of each bond multiply by the weight, i.e., one gets the equation (10) and (11):

$$
\begin{aligned}
& w_{A} \times D_{A}+w_{B} \times D_{B}+w_{C} \times D_{C}+\ldots+w_{n} \times \\
& D_{n}=D_{\text {portfolio }} \\
& \quad w_{A}+w_{B}+w_{C}+\ldots+w_{n}=1
\end{aligned}
$$

where w means the weight of each bond.

\subsection{Calculate the amounts of unit of bond in portfolio}

In order to calculate the amount of bond, one needs to know the present value of the portfolio and the weight of each bond following:

$$
\mathrm{U}_{\mathrm{A}}=\frac{\mathrm{FV}_{\text {portfolio }}}{(1+\mathrm{y})^{\mathrm{t}}} \times \frac{\mathrm{w}_{\mathrm{A}}}{\mathrm{PV}_{\mathrm{A}}}
$$

where $\mathrm{U}_{\mathrm{A}}$ means the amount of unit of bond $\mathrm{A}$.

Table 1. Key notation

\begin{tabular}{ll}
\hline Notation & Definition \\
\hline $\mathrm{D}$ & Macaulay Duration \\
$\mathrm{n}$ & maturity \\
$\mathrm{t}$ & time \\
$\mathrm{PV}$ & present value \\
$\mathrm{MD}$ & Modified Duration \\
$\mathrm{P}$ & price \\
$\mathrm{FV}$ & face value \\
$\mathrm{CF}$ & cash flow \\
$\mathrm{y}$ & yield to maturity \\
$\mathrm{g}$ & growth rate \\
$\mathrm{P} *$ & price after yield to maturity \\
& changing \\
w & weight \\
UA & amount of unit of bond A \\
\hline
\end{tabular}

Table 1 lists the definition of key notation mentioned in the equations above. In order to show the structure of bond and the weight of each bond in a portfolio more intuitively, the empirical test is presented in the section 3 .

\section{EMPIRICAL STUDY}

In this section, two kinds of bond are selected as examples forming a portfolio as a target. The two kinds of duration of bond will be investigated using duration to value the price of the asset and compared with the present value. Besides, the weight and the units of each bond will be calculated.

\subsection{Description of each bond and the portfolio}

Assume all debt considered in this exercise has the same level of default risk. The benchmark yield curve for fixed-income investments of the same riskiness is flat at a level of $4 \%$ p.a. The information of two bonds and portfolio is summarized Table 2 .

Table 2. Description of bonds and portfolio

\begin{tabular}{lclll}
\hline & $\begin{array}{l}\text { Face } \\
\text { value }\end{array}$ & $\begin{array}{l}\text { Current } \\
\text { price }\end{array}$ & $\begin{array}{l}\text { Annual } \\
\text { coupon }\end{array}$ & $\begin{array}{l}\text { Remaining } \\
\text { life }\end{array}$ \\
\hline Bond A & $£ 100$ & $£ 85.48$ & 0 & 4 years \\
Bond B & $£ 100$ & $£ 100$ & $£ 4$ & 2 years \\
Portfolio & $£ 17,000$ & & 0 & 3 years \\
\hline
\end{tabular}

\subsection{Solutions}

Assume all debt considered in this exercise has the same level of default risk. The benchmark yield curve for fixed-income investments of the same riskiness is flat at a level of $4 \%$ p.a.

\subsubsection{Calculate the Macaulay Duration for bond $A$ and bond $B$}

Table 3. FV and PV and PV multiply time of bond A

\begin{tabular}{llll}
\hline $\mathrm{t}$ & $\mathrm{FV}$ & $\mathrm{PV}$ & $\mathrm{t} \times \mathrm{PV}$ \\
\hline$\sum$ & 100 & 85.47 & 341.88 \\
\hline
\end{tabular}

As the bond $\mathrm{A}$ is a zero-coupon bond, i.e., the cash flow only happens in year 4, which is 100 . According to the Eq. (3), the present value equals to 85.47. Based on Eq. (1), the duration of bond A equals to 4 .

Table 4. CF, PV and PV multiply time of bond B

\begin{tabular}{|l|l|l|l|}
\hline $\mathrm{t}$ & $\mathrm{CF}$ & $\mathrm{PV}$ & $\mathrm{t} \times \mathrm{PV}$ \\
\hline 1 & 4 & 3.846 & 3.846 \\
\hline 2 & 104 & 96.154 & 192.308 \\
\hline$\sum$ & & 100 & 196.154 \\
\hline
\end{tabular}

The bond $\mathrm{B}$ is a fixed-coupon bond that the cash flow will happen in year 1 and 2. According to the Eq. (3), the present value of year 1 equals to 3.846 and the present value of year 2 equals to 96.154 . According to the Eq. (1), the duration of bond A equals to 1.972.

\subsubsection{Calculate the Modified Duration for bond $B$ and use Modified duration to estimate the price of bond}

The yield is assumed to increase $0.1 \%$ and $10 \%$. According to Eq. (2), the Modified Duration equals to 1.896. From the Eq. (8), if there is $0.1 \%$ change in yield, it will result $0.1896 \%$ in the price changes. Based on the Eq. (9), the price will be 99.8104, while the present value equals to 99.812 following Eq. (4). The error will 
be (99.812-99.8104)/99.812 $=0.0016 \%$, indicating that the approximation is nearly the same and the estimate is accurate.

Whereas, if there is $10 \%$ change in yield, it will lead to $18.96 \%$ in price change. Besides, the price will be 81.04 while the present value equals to 83.533 . On this occasion, the error will be (83.533-81.04)/83.533= $2.984 \%$.

The two numbers are not close and have a bigger difference. This is because using duration to calculate the price of the bond is just a linear approximation, but the function of yield is convex. Therefore, duration is a meaningful measure only if there is just a very small yield changes.

\subsubsection{Calculate how many units of each bond would need to form a portfolio above}

According to Eq. (13), the amount of bond A will be 90.133 and the amount of bond B will be 74.084 .

\subsection{Sensitive analysis}

In this part, the different impacts on present value and the amounts of units of different bonds will be discussed when elements changing.

\subsubsection{The effect on the change of present value when yield to maturity change}

The effects on present value when yield to maturity changes are evaluated based on the Eq. (3). The parameters are as follows: the face value is 5000, the annual coupon is 0 . Figure 5 depicts the curve of the present value and yield to maturity and the different curves when the maturity of bond is different.

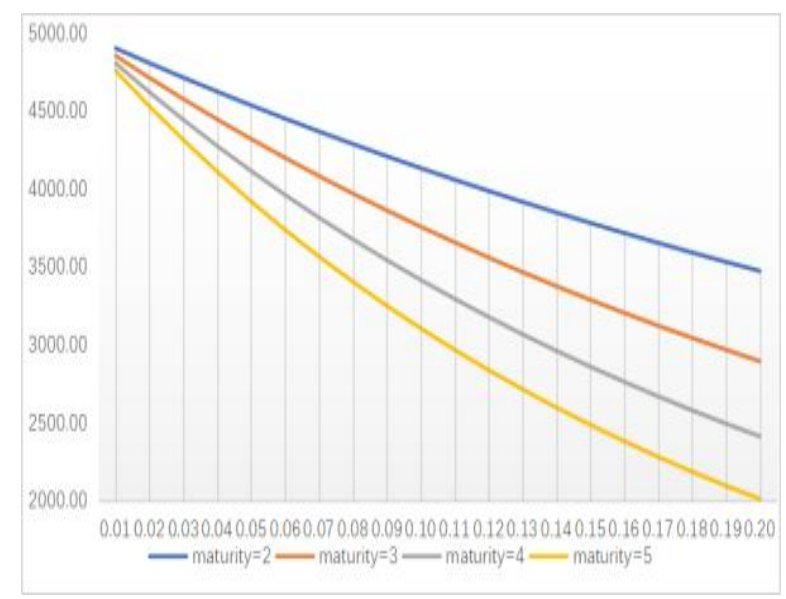

Figure 5 Curve of the present value and yield to maturity

Here comes the conclusion that with the change of the yield to maturity, the higher the yield to maturity is, the lower the present value will be. Moreover, they have convex relationship, the longer the maturity is, the bigger the slope of the curve will have.

\subsubsection{The effect on the change of present value when growth rate $(g)$ changes}

In this subsection, the influence on present value is demonstrated when growth rate $(\mathrm{g})$ changes according to the Eq. (5). The parameters are as follows: the face value is 5000 , the yield to maturity is $3 \%$. The figure 6 shows the curve of the present value and growth rate.

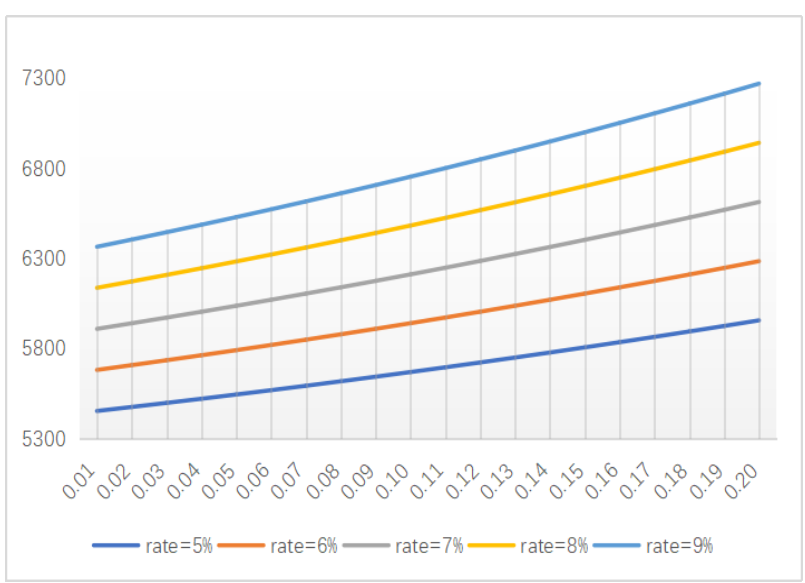

Figure 6 Curve of present value and growth rate

Figure 6 shows the different curves when the coupon rates of bond are different. Thus, one realizes that with the change of growth rate $(\mathrm{g})$, the present value has a positive relationship with it and there are convex curves. There is not huge difference between the different coupon rates, but the higher the coupon rate is, the bigger the slope will be.

\subsubsection{How the change of amounts of units of each bond in one portfolio will be if the yield to maturity changes with the duration of portfolio keep stable}

In this subsection, the effects are investigated on the amounts of units of bonds when yield to maturity changes according to the Eq. (13). The parameters are as follows: the face value of portfolio is 17000 , the weight of bond $\mathrm{A}$ is $50.98 \%$ and the weight of bond $\mathrm{B}$ is $49.02 \%$, the present value of bond $\mathrm{A}$ is 85.48 and the present value of bond B is 100 . Figure 7 displays the curve of the amounts and yield to maturity. 


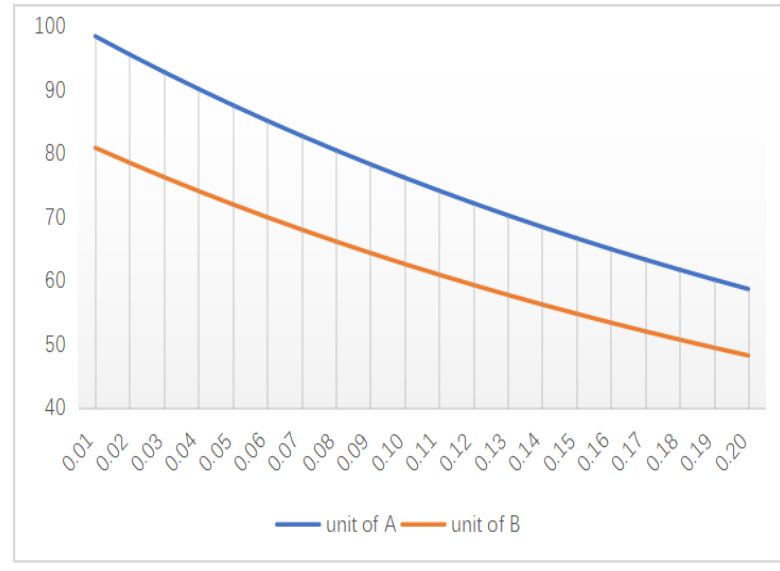

Figure 7 Curve of amount and yield to maturity

As shown in the graph, with the change of yield, the higher the yield is, the small the amounts of units of each bond will be and they have a negative and convex relationship.

\section{DISCUSSION}

Nevertheless, there are some drawbacks and limited assumptions of the duration model. Firstly, the duration model has an assumption that the price can be affected by the variation of yield to maturity straight according to Eq. (8). However, based on the sensitive analysis, the real relationship between the bond price and the yield to maturity is not linear (convexity according to the Figure 6). Thus, the relationship between the price and the change of yield to maturity is not linear. There might be error when estimate the price by using duration.

Secondly, the duration model adopts the same discount rate for all cash flows. According to the Eq. (1) (2) and (4), the present values are calculated by using the same discount rate. However, the discount rate will change with the time following the real way shown in the Eq. (6). Therefore, there may cause error when calculate the price of bond when using duration. There might be different kinds of relationship between yield to maturity and maturity e.g., flat positive, negative and vaulted (Seen from Fig. 8-11 accordingly).

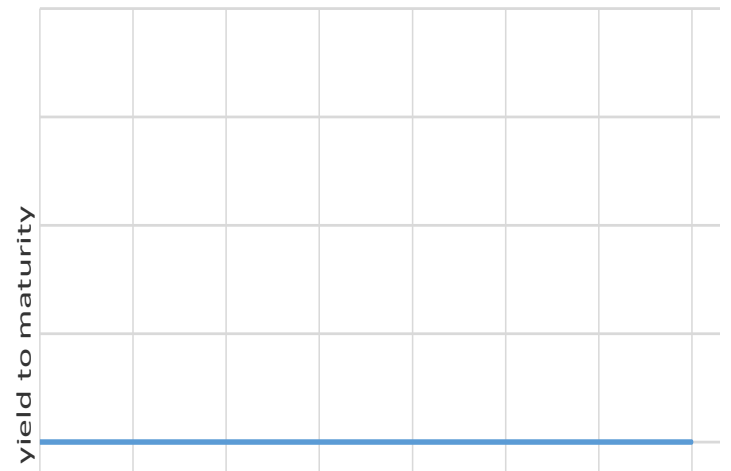

Figure 8 Flat relationship

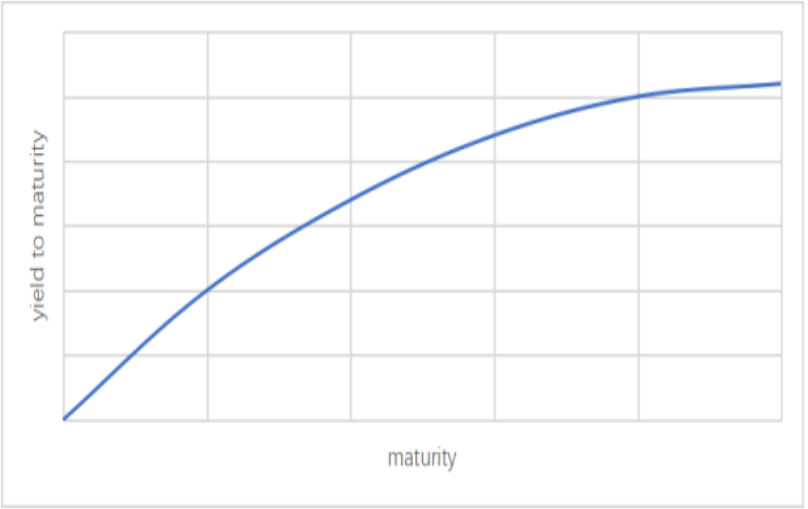

Figure 9 Positive relationship

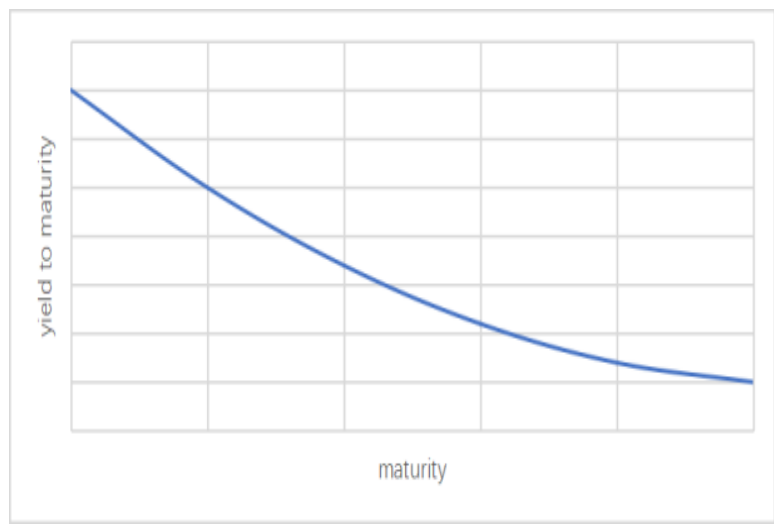

Figure 10 Negative relationship

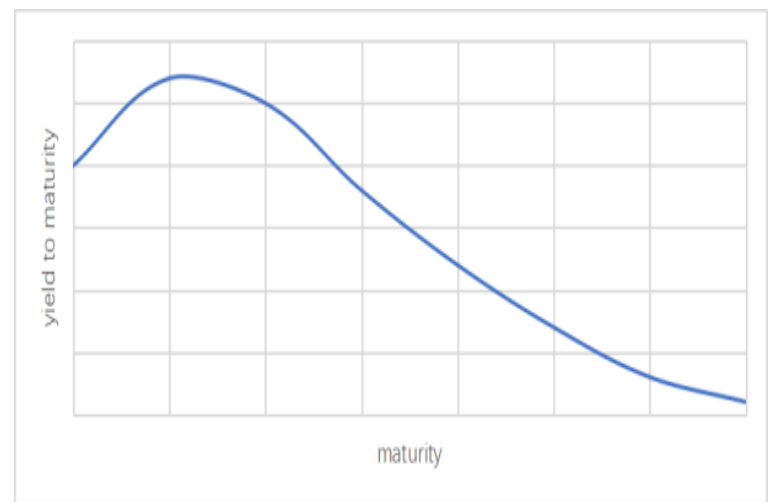

Figure 11 Vaulted relationship

Thirdly, the duration model assumes the parallel shifts of the yield curve. In fact, due to the influence of time, the responses of yields with different maturities are different as illustrated in Figure 6. One finds that the longer the maturity and the duration are, the more risk the bond will be since there will be higher probability of change in interest rate.

Lastly, the duration model assumes that when the interest rate changes, the future cash flow will not change. However, in most cases, the future cash flows will generally change with the interest rates, and their prices will also change. In this situation, there will have error with this model. 


\section{CONCLUSION}

In summary, the important role of valuation model in asset allocation is investigated for duration model, which is a good way to show the rate of weighted cash flow and the unweighted cash flow. For study the valuation model by using duration and the way to allocate the asset, a model of duration is conducted to evaluate asset like bond, which paves paths to calculate the present value of different kinds of bonds and the weight of bond in portfolio in order to allocate the assets. After studying methods, the empirical test and the sensitive analysis are carried out to find more characters of duration model. Based on the results, the duration model can be used as an efficient model for asset evaluation and allocation. However, this model will have huge error when the yield to maturity changes a lot. There also have some assumptions in this definition which do not correspond with reality, i.e., will have some error with the price calculated by duration model and true present value. Anyway, these results offer a guideline for asset appraisal and further studies will focus on model refinement with larger datasets.

\section{REFERENCES}

[1] A, T. V. L. , A, S. V. U., A, J. X. , \& B, T. V. W. . Designing pricing and compensation schemes by integrating matching and routing models for crowd-shipping systems. Transportation Research Part E: Logistics and Transportation Review, 149.

[2] A, M. R., B, A. R. Y., A, A. A. , \& A, S. M. M. . (2021). Numerical pricing based on fractional black - scholes equation with time-dependent parameters under the cev model: double barrier options. Computers \& Mathematics with Applications, 90, 104-111.

[3] Siu, T. K. , \& RJ Elliott. (2020). Bitcoin option pricing with a setar-garch model. European Journal of Finance(1), 1-32.
[4] María A. Baamonde-Seoane a, María del Carmen Calvo-Garrido a, B, M. C. , \& Carlos Vázquez a. (2021). Numerical solution of a nonlinear pde model for pricing renewable energy certificates (recs). Applied Mathematics and Computation.

[5] Hens, \& Naebi. (2021). Behavioural heterogeneity in the capital asset pricing model with an application to the low-beta anomaly. Applied Economics Letters.

[6] Ge, Y., Chen, H., Zou, L. , \& Zhou, Z. . (2021). Political background and household financial asset allocation in china. Emerging Markets Finance and Trade(5), 1-15.

[7] Shen, C. , Zhang, T. , \& Chen, Y. . (2021). The role of white precious metals in the allocation of general asset. Journal of Systems Science and Complexity(2).

[8] Du, K. , Huang, J. , \& Wu, Z. . (2019). Relationship between backward and forward linear-quadratic mean-field-game with terminal constraint and optimal asset allocation for insurers and pension funds. International Journal of Control, 1-15.

[9] Huang, Z. , \& Lu, Y. . (2021). Analysis of asset risk and household financial asset allocation structure - empirical analysis from a nonlinear model. E3S Web of Conferences, 235, 01039.

[10] H Kato, \& Hibiki, N. . (2020). Asset allocation with asset-class-based and factor-based risk parity approaches. Journal of the Operations Research Society of Japan, 63(4), 93-113.

[11] Shah, S. , Sukmana, R. , \& Fianto, B. A. . (2020). Macaulay's theory of duration: 80-year thematic bibliometric review of the literature. Journal of Economic Studies, ahead-of-print(ahead-of-print). 